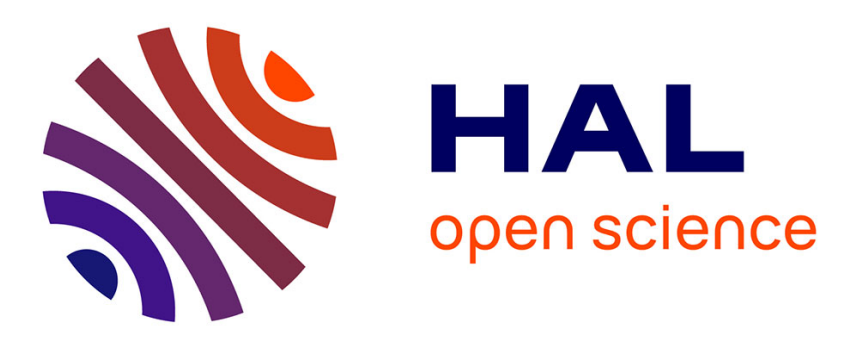

\title{
Optimization of magnetic retention in the gastrointestinal tract: Enhanced bioavailability of poorly permeable drug
}

Anjali Seth, David Lafargue, Cécile Poirier, Thomas Badier, Nathalie Delory, Alain Laporte, Jean-Marie Delbos, Véronique Jeannin, Jean-Manuel Péan, Christine Ménager

\section{To cite this version:}

Anjali Seth, David Lafargue, Cécile Poirier, Thomas Badier, Nathalie Delory, et al.. Optimization of magnetic retention in the gastrointestinal tract: Enhanced bioavailability of poorly permeable drug. European Journal of Pharmaceutical Sciences, 2016, 10.1016/j.ejps.2016.12.022 hal-01427399

\section{HAL Id: hal-01427399 https://hal.sorbonne-universite.fr/hal-01427399}

Submitted on 5 Jan 2017

HAL is a multi-disciplinary open access archive for the deposit and dissemination of scientific research documents, whether they are published or not. The documents may come from teaching and research institutions in France or abroad, or from public or private research centers.
L'archive ouverte pluridisciplinaire HAL, est destinée au dépôt et à la diffusion de documents scientifiques de niveau recherche, publiés ou non, émanant des établissements d'enseignement et de recherche français ou étrangers, des laboratoires publics ou privés. 


\title{
WILEY-VCH
}

DOI: $10.1002 /(($ please add manuscript number))

\section{Full paper}

\section{Optimization of Magnetic Retention in the Gastrointestinal Tract: Enhanced}

Bioavailability of Poorly Permeable Drug

By Anjali Seth, David Lafargue, Cécile Poirier, Thomas Badier, Nathalie Delory, Alain

Laporte, Jean-Marie Delbos, Véronique Jeannin, Jean-Manuel Péan and Christine Ménager*

Dr A. Seth, Prof. C. Ménager*

Sorbonne Universités, UPMC Univ Paris 06, CNRS, UMR 8234, PHENIX, F-75005, Paris, France.

Dr David Lafargue, Dr Cécile Poirier, Thomas Badier, Nathalie Delory, Alain Laporte, JeanMarie Delbos, Véronique Jeannin, Dr Jean-Manuel Péan

Technologie Servier, 25/27 rue Eugène Vignat, 45000 Orléans, France

E-mail: christine.menager@upmc.fr

Keywords: Oral delivery, Magnetic retention, Magnetic beads, Dual imaging, Pharmacokinetic.

\begin{abstract}
Oral administration of low permeable drugs remains a challenge as they do not cross biological membrane efficiently and therefore exhibit a poor bioavailability. Herein, the effect of magnetic retention on the circulation and bioavailability of magnetic beads in the gastrointestinal tract in the presence of an external magnetic field is evaluated. Retention efficiency is imaged using magnetic resonance and near infrared techniques. The effect on
\end{abstract}




\section{WILEY-VCH}

bioavailability is then evaluated in a pharmacokinetic study. Iron oxide nanoparticles, the drug (dipeptidyl peptidase-IV inhibitor) and a fluorophore (Alexa Fluor-750) are coencapsulated in chitosan-alginate core-shell beads. Retention of these beads is induced by the presence of an external permanent magnet on the abdomen of rats. After single administration of magnetic beads containing $20 \mathrm{mg} / \mathrm{kg}$ of drug to fasted rats, a 2.5 -fold increase in drug's bioavailability is observed in the presence of an external magnetic field, significantly higher than the same dose administered to rats without the field or for the drug in aqueous solution. Retention of the magnetic carriers in the presence of an external magnet proves to accumulate these carriers in a specific localization of the intestine leading to a significant improve in the drug's bioavailability.

\section{Introduction}

Bioavailability of oral drugs remains low because of the harsh gastrointestinal tract (GIT) environment. One of the major drawback of using the oral route to deliver drugs is that these molecules need to cross biological membranes in order to pass to the bloodstream and reach their physiological target. The large mucosal surface area of GIT presents opportunities as well as challenges, the former for retention of nanoparticles or microdevices and the latter as additional transport barriers (Chen and Langer, 1998; Gamboa and Leong, 2013; Reed and Wickham, 2009; You et al., 2015). A large number of drugs with high clinical potential have not yet been employed because of their limited bloodstream access. In this context, a growing attention has been focused over the past few decades on the design and manufacturing of advanced formulations intended for the release of bioactive compounds to selected regions of the GIT. By controlling the site of drug liberation throughout the gut, it would be possible to limit the tolerability issues associated with treatments that mainly affect specific GI districts, enhance the bioavailability of drugs that show regional differences in their stability and/or 


\section{WILEY-VCH}

permeability profiles or, alternatively, improve the therapeutic outcome in the management of widespread local pathologies (e.g. phlogosis, ulcers, microbial infections, motility disorders). Gastroretentive pills have been investigated for decades because increasing the residence time of pills in the stomach would greatly benefit the numerous narrow absorption window therapeutics that are primarily absorbed in the proximal small intestines (Davis, 2005; Gröning et al., 1998; Nayak et al., 2010; Polyak and Friedman, 2009; Streubel et al., 2006). The most prevalent strategies for achieving gastric retention are density mismatching, geometry-based, and bioadhesive pills (Andrews et al., 2009; Bhardwaj et al., 2011; Chirra et al., 2014; Eiamtrakarn et al., 2002; Helliwell, 1993; Salamat-Miller et al., 2005; Whitehead et al., 2004; Wittaya-areekul et al., 2006). The use of magnetic force has also been described in order to increase the residence time of magnetic microparticulates. Previous studies have used static external magnets to improve the bioavailability of orally administered proteins including insulin for diabetics (Chen and Langer, 1998, 1997; Cheng et al., 2006; Häfeli, 2004), narrow absorption window (NAW) therapeutics such as acyclovir as an antiviral therapy (Chirra et al., 2014; Gamboa and Leong, 2013; Gröning et al., 1998) and therapeutics for site-specific pathologies including bleomycin for esophageal cancer (Ito et al., 1990; Nagano et al., 1997). However, the magnetic force required for pill immobilization has rarely been taken into account. Two studies bring considerably more insight in the field of magnetic pill retention as a safe method to target specific window and improve the bioavailability of drugs. E. Mathiowitz and coworkers reported a method, which enables tracking and localization of a magnetic pill (Laulicht et al., 2010). In a second publication the authors' study was focused on the forces experienced by an orally ingested magnetic pill, tracked by Hall array sensors. This paper presents a quantitative analysis of inertial net forces experienced by magnetic model pills during gastric residence in humans and two preclinical animal models both in fasted and fed states (Laulicht et al., 2011). They point out very 


\section{WILEY-VCH}

important facts as the necessity to quantify the magnetic force involved, in order to have a feedback of the magnetic retention.

The orally active dipeptidyl peptidase-IV (DPP-4) inhibitor used in this study is currently developed for the treatment of type 2 diabetes mellitus (T2DM). In vivo, DPP4 rapidly inactivates incretins (GLP-1 and GIP) secreted by the intestinal cells, which stimulate glucose-induced insulin synthesis and secretion in response to food intake. However DPP4 inhibitors exhibit a very low oral bioavailability associated with a narrow absorption window in the upper part of the intestine as many highly hydrophilic molecules (acyclovir, amoxicillin, metformin) (Amidon et al., 1995; Lindenberg et al., 2004). Due to that, we propose to enhance the bioavailability of DPP4 inhibitors by using the magnetic retention technique.

We designed magnetic core-shell chitosan-alginate beads as theranostic carriers (Fig. 1a-c). The magnetic nanoparticles used to fabricate the magnetic beads are biocompatible iron oxide nanoparticles (M. Levy et al., 2011). These nanoparticles exhibit superparamagnetic behavior and are $T_{2}$ (negative) contrast agents in MRI (Magnetic Resonance Imaging) (Fig. 1d). According to a covalent coupling between the polymer and a fluorophore, dynamics of the beads along the intestine is visualized by near infra-red (NIR) microscopy during 6 hours after beads administration (Fig. 1e). These magnetic beads were orally administrated to rats. A pharmacokinetic study was performed to quantify the amount of drug in plasma (Fig. 1f). The magnetic beads associated with an external magnet enabled investigation of the benefits of magnetic accumulation when compared to free drug and non-targeted beads. Finally, the safety of the magnetic beads was investigated using iron titration of the organ as well as histological examination of intestinal tissue. 


\section{WILEY-VCH}

\section{Materials and Methods}

\section{1. Materials}

All chemical reagents were purchased from Sigma-Aldrich, France. Animals were provided from Charles River, France. Gelatin capsules (size 9: $2.65 \mathrm{~mm}$ x $8.6 \mathrm{~mm}$ ) and cannulas (4 mm x $220 \mathrm{~mm}$ ) used to force feed the rats were respectively provided from Torpac and Ecimed, France. The fluorescent probe, Alexa Fluor-750 Carboxylic Acid Succinimidyl Ester was purchased from Life Technologies, France.

\section{2. Model drug}

The drug used in this study was kindly provided by Technologie Servier (Fig. S1). This compound is a white powder soluble in water, highly hygroscopic which belongs to the chemical class of cyanopyrrolidines. This orally active dipeptidyl peptidase-IV (DPP-4) inhibitor is currently developed for the treatment of type 2 diabetes mellitus (T2DM). In vivo, DPP4 rapidly inactivates GLP-1 and GIP, incretins secreted by the intestinal cells, which stimulate glucose-induced insulin synthesis and secretion in response to food intake. The development of this active pharmaceutical ingredient has been delayed due to low oral bioavailability caused by its very poor intestinal permeability. This drug is classified as a Class III molecule (Biopharmaceutical Classification System, 2011; Amidon et al., 1995; Blume and Schug, 1999). This means that that the drug exhibits a very high solubility (12 $\mathrm{mg} / \mathrm{mL}$ in phosphate buffer at $\mathrm{pH}$ 6) and a very low membrane permeability (Absorbed fraction on Caco-2 model is under 30\%), (Y. Sambuy, 2005; P. Artursson et al., 1991; P. V Balimane et al., 2005). The physicochemical properties of the drug are: $\mathrm{Mw}=769 \mathrm{~g} / \mathrm{mol}$; $\mathrm{pKa}$ $=7.4$ and 3.5; Partition coefficient: $\log \mathrm{P}=-1.11, \log \mathrm{D}=-1.4$ at $\mathrm{pH}$ 7.4.

\section{3. Magnetic nanoparticles synthesis}

The superparamagnetic particles were synthesized according to Massart's procedure ( Massart, R. , 1981; Canfarotta, F. et al., 2014). Magnetite $\left(\mathrm{Fe}_{3} \mathrm{O}_{4}\right)$ nanocrystals were prepared by alkaline coprecipitation of $\mathrm{FeCl}_{3}(1.5 \mathrm{~mol})$ and $\mathrm{FeCl}_{2} \cdot 4 \mathrm{H}_{2} \mathrm{O}(0.9$ mol$)$ salts in 


\section{WILEY-VCH}

alkaline solution $\left(\mathrm{NH}_{4} \mathrm{OH}, 7 \mathrm{~mol}\right)$. In order to be completely oxidized from magnetite into maghemite $\left(\gamma-\mathrm{Fe}_{2} \mathrm{O}_{3}\right)$, the solid phase was separated from the supernatant and immersed in a boiling solution of ferric nitrate $\left(0.8 \mathrm{~mol}\right.$ in $0.8 \mathrm{~L}, 30 \mathrm{~min}$ at $\left.90-100{ }^{\circ} \mathrm{C}\right)$. After washing steps in acetone and diethyl-ether to remove the excess ions, the nanoparticles readily dispersed in water and formed a true "ionic ferrofluid" made of maghemite nanoparticles. The iron oxide surface bore a positive charge due to adsorption of protons in acidic media $\left(\mathrm{HNO}_{3}, 4 \mathrm{~mol}\right.$, solution at $\mathrm{pH}$ between 1.2 and 1.7). On the microscopic scale, this colloidal suspension of maghemite nanoparticles exhibit a Log-Normal distribution of diameters with parameters $d_{0}=$ $7.5 \mathrm{~nm}$ and $\sigma=0.35$, as measured by vibrating sample magnetometry (VSM). The final iron content was checked by atomic absorption spectrometry $(\mathrm{AAS})\left(\mathrm{C}_{\mathrm{Fe}}=1.3 \mathrm{~mol} \cdot \mathrm{L}^{-1}, \mathrm{~m}_{\mathrm{Fe}}=104\right.$ $\mathrm{g} / \mathrm{L}$ and volume fraction $\Phi=2 \%$ ). The colloidal suspension was ready to use and is stable at room temperature for years.

\section{4. Fluorescent and magnetic chitosan-alginate core-shell beads preparation}

Fluorescent and magnetic chitosan alginate core-shell beads containing the drug were prepared as previously described using a standard extrusion crosslinking method (Seth et al., 2014). Briefly, chitosan solution was prepared by dissolving chitosan $5 \% \mathrm{w} / \mathrm{v}$ in deionized water containing 5\% v/v acetic acid. The fluorescent probe, Alexa Fluor-750, was grafted onto the chitosan polymer via a covalent coupling. Succinimidyl ester moieties on the fluorophore reacted with primary amino groups of the chitosan backbone. Alexa Fluor-750, previously dissolved in DMSO $(1 \mathrm{mg} / 100 \mu \mathrm{L})$, was added to the mixture, $2 \% \mathrm{v} / \mathrm{v}$, and was allowed to react for 1 hour at room temperature under magnetic stirring. Thereafter, $50 \% \mathrm{v} / \mathrm{v}$ of magnetic nanoparticles (MNPs) in water was added to the dye-polymer mixture under stirring for 10 minutes. Finally, $10 \%$ w/v of the drug was then added and the mixture was allowed to further stir for another 30 minutes. The resulting solution was added drop wise in a gently stirred water bath $(10 \mathrm{~mL})$ containing TPP $(2 \% \mathrm{w} / \mathrm{v})$ and Alginate $(1 \% \mathrm{w} / \mathrm{v})$ by extrusion through a syringe needle (inner diameter of $0.45 \mathrm{~mm}$ ). Size of the beads was 


\section{WILEY-VCH}

controlled by the diameter of the syringe needle $(0.45 \mathrm{G})$ and the flow rate $(10 \mathrm{~mL} / \mathrm{min})$ of the syringe pump. An optimal height of $30 \mathrm{~cm}$ was used to obtain spherical beads. The beads were then allowed to crosslink for 30 minutes under gentle magnetic stirring and subsequently collected by magnetic decantation and rinsed in deionized water. Beads were let to dry at room temperature for 24 hours prior to be used. The reticulation bath and washing water were kept for further analysis.

\section{5. In vitro release study}

Drug release from the beads was tested using a Sotax ${ }^{\circledR}$ dissolution bath apparatus. Beads were introduced in a $500 \mathrm{~mL}$ bath at $\mathrm{pH}=6.8$ to mimic intestinal environment and agitated at 50 $\mathrm{rpm}$ at a fixed temperature of $37^{\circ} \mathrm{C}$. Dissolution media was prepared by mixing $136.1 \mathrm{~g}$ of potassium dihydrophosphate and $17.9 \mathrm{~g}$ of sodium hydroxide in $20 \mathrm{~L}$ of distilled water. Every fifteen minutes, a fixed volume was automatically withdrawn and the amount of drug was measured by UV spectrometry. Detection occurs at $\lambda=248 \mathrm{~nm}$.

\section{6. Iron titration by $A A S$}

The total iron content of the ferrofluid, magnetic beads or organs was determined by atomic absorption spectroscopy (AAS) equipped with a Perkin-Elmer Analyst 100 apparatus after degrading the samples in boiling $\mathrm{HCl}(37 \%)$.

\section{7. Scanning electron microscope (SEM) characterization}

The magnetic core-shell beads were observed by SEM just after preparation (wet) or after overnight drying. The wet samples were dehydrated through concentration gradient of ethanol (30-50-70-96-100\%) before critical point drying (CPD 7501, Quorum Technologies). Samples were directly mounted on stubs, or manually freeze-fractured after a fast plunging in liquid nitrogen and then gold-sputtered (Scancoat Six, Edwards). Observation was carried out with a conventional SEM operating at $15 \mathrm{kV}$ (Cambridge Stereoscan S260). 


\section{WILEY-VCH}

\section{8. Magnetometry measurements}

Magnetic moment and magnetization measurements were performed on a Quantum Design Ltd. MPMS superconducting quantum interference device (SQUID) magnetometer. Samples were prepared as follows: one magnetic and fluorescent chitosan alginate core-shell bead was introduced in a poly-methyl methacrylate (PMMA) cell sealed with a PMMA cap and nonmagnetic glue. From the magnetic measurement realized on one magnetic bead we can deduce the magnetic moment of the bead $\left(\mathrm{emu}=1.10^{-3} \mathrm{~A} \cdot \mathrm{m}^{2}\right) v s$ the magnetic field intensity $\left(\right.$ Gauss $\left.=1 \cdot 10^{3} \mathrm{~A} \cdot \mathrm{m}^{-1}\right)$.

\section{9. Calibration of the magnetic field gradient for in vivo experiments}

A cylindrical neodymium iron boron magnet (diameter $20 \mathrm{~mm}$, length $10 \mathrm{~mm}$, Supermagnete ${ }^{\circledR}$ ) was used for in vivo experiments. Magnetic field intensity was measured using a Hall-effect sensor from the center of the magnet at a distance ranging from 0 to $5 \mathrm{~cm}$. Magnetic field intensity is 2560 Gauss when in contact with the magnet.

Animal care. Male Wistar rats, 10 to 12 weeks old and about $300 \mathrm{~g}$ weight, were housed under barrier environment in Servier's Experimental Animal Center. All rats were maintained in an air-conditioned room and subjected to 12-h dark/light cycles. Animals were handled in accordance with the guidelines of Servier's Animal Care Council. All rats were fasted 12 hours before the experiments but were allow free access to water.

\section{10. Ultrasound imaging for placement of the magnet on the rat abdomen}

A portable ultrasound apparatus (SonoSite EDGE, Fujifilm) was used to visualize the position of the stomach of each rat under anesthesia. Once the position of the stomach and the beginning of the duodenum localized a steel pinch was used to create an artefact in order to mark the desired position of the magnet. Position of the pylorus was label with a marker on the rat's abdomen. Magnet is then placed on the rat abdomen using the marked position to ensure that the magnet is placed on the stomach-duodenum's junction and fixed using 


\section{WILEY-VCH}

adhesive tape. Magnet was placed on rats' abdomen one hour before the start of the experiments.

\section{11. In vivo bioavailability study}

Male Wistar rats weighted $300 \mathrm{~g}$ and aged 10 weeks old were fasted prior to magnetic beads administration. 16 fluorescent and magnetic beads were conditioned in 2 gelatin capsules and administered by force feeding through a cannula going to the stomach of the rat in order to administer a drug dose of $20 \mathrm{mg} / \mathrm{kg}$. $1 \mathrm{~mL}$ of drinking water was then given to the rat to aid dissolution of the capsule and liberation of the beads in the stomach. At $0.5,1,2,3,4$ and 6 hours after gavage, $300 \mu \mathrm{L}$ of blood were withdrawn from the rats at the jugular vein. Blood samples were then centrifuged and $150 \mu \mathrm{L}$ of plasma were recovered and mixed with $9 \mu \mathrm{L}$ of hydrochlorydric acid $2 \%$ before storage at $-80^{\circ} \mathrm{C}$ prior analysis by mass spectrometry. Drug content in rat's plasma was then measured using MS/MS mass spectrometry (API $4000^{\mathrm{TM}}$, ABSciex) coupled to UPLC chain (Acquity, Waters).

Statistical analysis was performed using a Student's $t$-test. $P$-values less than 0.05 were considered statistically significant.

\section{12. Magnetic Resonance Imaging (MRI)}

A 4.7 Tesla MRI apparatus (Biospec 47/40 USR, Brüker) was used to acquired sagittal plans images of the rats under isoflurane anesthesia at several selected times 1, 2, 4 and 6 hours after force feeding the rats with the beads. A "turbo RARE" spin echo sequence was used $\left(90^{\circ}+180^{\circ}\right.$ impulsions $)$ with parameters: $\mathrm{TR}=1000 \mathrm{~ms}, \mathrm{TE}=20 \mathrm{~ms}$, "RARE factor" $=4$. Geometry parameters were: FOV (field of view) $=8 * 8 \mathrm{~cm}$, matrix $=256 * 256$ and resolution $=$ $312 * 312 \mu \mathrm{m}$

\section{13. Near infrared fluorescence imaging}

An infrared camera (ORCA II - BT- 512 C4742-98-26, Hamamatsu Photonics) was used to acquire the fluorescence images. At several selected times 1, 2, 4 and 6 hours after force feeding the rats with the beads, animals were sacrificed by exsanguination after isoflurane 


\section{WILEY-VCH}

anesthesia. The skin was removed under the position of the magnet. Bright field and fluorescence images were then acquired to visualize the beads under the magnet. Thereafter, the rib cage was open and the intestine was observed from the stomach to the caecum. Bright field and fluorescence images were acquired to localize the beads along the intestine. Images were then processed using an acquisition and processing software (HiPic 6.4.1 and Wasabi, Hamamatsu Photonics).

\section{14. Iron titration in the organs}

The iron content of the liver, spleen and faeces of the rats were determined by AAS and compared for two groups of three rats. The first group was the control group and the second group was rats 24 hours after administration of the magnetic beads using magnetic retention for 6 hours. The faeces were collected twice, from the beginning up to 6 hours after beads administration and from 6 to 24 hours after the beginning of the experiment. At $t+24$ hours, the rats were sacrificed by exsanguination and the spleen and liver were collected. Then all the samples were degraded in $\mathrm{HCl} 37 \%$ and the iron content was determined by AAS.

\section{15. Histology study}

After the last blood sampling at $t+6$ hours after administration of the beads, the animals were sacrificed by exsanguination. Several tissues (liver, spleen, fore stomach and glandular stomach, duodenum, jejunum, ileum and caecum) of the rats were harvested and stained with Prussian blue and/or hematoxylin and eosin staining for inclusion in paraffin block and histological microscopic analyses (Olympus BX 41) (R. Bahnemann et al., 1995).

\section{Results}

\subsection{Magnetic retention: Fabrication of the magnetic carriers}

\subsubsection{Release properties of the chitosan alginate core-shell beads}

Millimeter sized fluorescent magnetic chitosan-alginate core-shell beads were designed using a cross-linking process. First, chitosan polymer was marked by a flurophore (Alexa Fluor- 


\section{WILEY-VCH}

750). Succinimidyl ester moieties of the fluorophore were covalently linked on the primary amino groups of the polymer. Fluorescent chitosan $(5 \%$ w/v) was mixed with magnetic nanoparticles $(50 \% \mathrm{v} / \mathrm{v})$ and drug $(10 \% \mathrm{w} / \mathrm{v})($ Fig. S1). This mixture was then injected through a syringe needle in a crosslinking aqueous solution containing tripolyphosphate (TPP) $2 \% \mathrm{w} / \mathrm{v}$ and alginate $1 \% \mathrm{w} / \mathrm{v}$. TPP ions allow reticulation of the chitosan core whereas alginate precipitates at the shell due to its low solubility in acid $\mathrm{pH}$. Alginate shell $(30 \mathrm{~nm}$ thick) was clearly observed by SEM (Fig. 2b). The entrapment efficiency (EE\%) of the drug was calculated using an indirect titration method. Amount of free drug that has not been able to be encapsulated into the beads was measured in the recovered crosslinking supernatant by HPLC using the standard HPLC titration method for the drug. Entrapment efficiency could then be calculated with the following equation (Eq.1): $E E(\%)=\frac{\text { (total drug amount }- \text { amount of free drug in the supernatant) }}{\text { total drug amount }}$

Entrapment efficiency in the beads was very high, $\mathrm{EE} \%=75 \%$, compared to other formulations with this type of biopolymer (Hari et al., 1996; Seth et al., 2014; Sezer et al., 1999; Zhang et al., 2013). The mean composition for each bead was water $(83.76 \%)$, biopolymer $(5.0 \%)$, drug $(6.64 \%)$ and MNPs (4.6\%) in weight before drying. After drying overnight, one bead contained $368 \mu \mathrm{g}$ of iron (approximately $10^{15} \mathrm{MNPs}$ ) and $0.5 \mathrm{mg}$ of drug. The mean composition for dry bead was chitosan $(30.7 \%)$, drug $(40.8 \%)$ and MNPs $(28.3 \%)$ in weight. This composition will be suitable for in vivo experiments. The alginate shell is expected to prevent beads degradation when passing through the stomach region as this biopolymer is strongly insoluble in acidic pH (B. A. Teply et al., 2008; J. K. Vasir et al., 2003; F.-Q. Wang et al., 2011; K. Suknuntha et al., 2011). Moreover, alginate coating of chitosan magnetic beads allowed drug release to follow a linear kinetic profile within $2 \mathrm{~h}$ for wet beads (Fig. 2a and 2d) and is extended to 6 hours for dry beads (Fig. 2c and 2d). No release of magnetic nanoparticles or fluorophore occurred throughout experiment time and 


\section{WILEY-VCH}

drug release was only due to passive diffusion. The iron concentration has been titrated in the released buffer at the end of each experiment to determine whether some MNPs were released from the biopolymer matrix. During the time of the experiment no iron was detected in the media.

\subsubsection{Magnetic properties of chitosan-alginate core-shell beads}

The magnetic and fluorescent beads exhibit a superparamagnetic behavior like the MNPs themselves (Fig. S2A). The encapsulation did not induce any changes in their magnetic properties. The magnetic moment of one bead was measured using vibrating sample magnetometry (VSM) as a function of the applied magnetic field (Fig. S2A). The distance between the external magnet and the pylorus was experimentally determined to be $5 \mathrm{~mm}$. According to the calibration of the magnet (Fig. S2B), the value of the magnetic field is B = 611 Gauss $(\mathrm{z}=5 \mathrm{~mm})$. The magnetic force applied on the bead was calculated using the following equation (Eq. 2): $F_{m, z}=\mu_{z} \cdot \frac{d_{B z}}{d_{z}}$.

Where $\mu_{\mathrm{z}}$ is the magnetic moment of the bead, $\mu_{\mathrm{z}}=0.01910^{-3} \mathrm{~A} \cdot \mathrm{m}^{-2}(\mathrm{z}=5 \mathrm{~mm}$ and $\mathrm{B}=611$ Gauss) and $\frac{d B z}{d z}$ the magnetic field gradient $=12 \mathrm{~T} \cdot \mathrm{m}^{-1}(\mathrm{z}=5 \mathrm{~mm})$. The value of the magnetic force is $F_{\mathrm{m}, 5 \mathrm{~mm}}=0.23 \mathrm{mN}$.

\subsection{Magnetic retention: imaging study}

\subsubsection{Magnetic Resonance Imaging}

Due to their superparamagnetic properties, the beads can be easily visualized in MRI. Each bead containing a high amount of MNP $\left(10^{15} \mathrm{MNPs} /\right.$ bead $)$ induces a negative contrast on $\mathrm{T}_{2}$ weighted MR images (Fig. 1d). MRI study allows the localization of beads along the GI tract of rats. Imaging was performed on two groups of rats ( $n=3$ per group). In the first group, a magnet was placed on the abdomen of animals before the start of the experiment using ultrasound imaging to locate the stomach-duodenum junction. The second group was the 


\section{WILEY-VCH}

control group, animals without magnet on the abdomen. MR images (sagittal plans) have been acquired at 1, 2, 4 and 6 hours after administration of the beads to the rats by force-feeding in the stomach. Position of the beads along the GI tract can be visualized on the images as darker spots thanks to the negative contrast of magnetic beads (Fig. 3). For easier interpretation, position of the stomach and initial magnet placement were marked on the images respectively by red and yellow circles. One hour after administration, the beads were localized in the stomach for both groups (Fig. 3a and 3e, red circle). At $t+2$ hours, some of the beads were still localized in the stomach and others began to circulate within the intestine for both groups (Fig. 3b and 3d, red and yellow circles). The lack of differences between the two groups for shortest times can be explained by gastric emptying time. Beads are staying in the stomach before being pushed along the intestine. For latest times $(t+4$ and $t+6$ hours $)$, localization of the beads along the GI tract becomes clearly different between the two groups. At $t+4$ and $t$ +6 hours, it can be clearly observed that the dark zone corresponding to the magnetic beads was localized under the magnet position (Fig. 3c and 3d, yellow circle. For the control groups, beads were not grouped in a special area (Fig. $3 \mathrm{~g}$ and $3 \mathrm{~h}$, yellow circle). When the magnet was used in order to induce magnetic retention of the beads in the GI tract, the negative contrast due to the accumulation of the beads containing MNPs was observed localized under the initial position of the magnet. On the contrary, for the control rats without magnet, the beads could not be localized at a specific position. However, as the whole intestine was highly folded, all the loops could not be discriminated using MRI only. Therefore, NIR fluorescence was used as an additional imaging technique for further investigation of the magnetic retention of the beads in the intestines.

\subsubsection{Near Infra-Red Fluorescence}

The same protocol was used to image the beads using NIR fluorescence. Two groups of rats ( $n=3$ per group) were studied. One group with magnet placed on the abdomen of animals before the start of the experiment to study magnetic retention and one group as a control 


\section{WILEY-VCH}

without magnetic retention. For the times $t+1,2,4$ and 6 hours after beads administration, fluorescence images were acquired first in the whole animal, under the initial position of the magnet (Fig. 4A). For the control group, at $t+1$ and 2 hours, the fluorescence was localized under the magnet position (Fig. 4A e and f). At $t+4$ and 6 hours, fluorescent intensity could no longer be observed under the initial magnet position (Fig. 4A g and h). For rats with the magnet, fluorescence intensity was strong and localized under the magnet position for every times ( $t+1,2,4$ and 6 hours) (Fig. 4A a-d), indicating that the beads were accumulated under the magnet position throughout the time of the experiment. After the first imaging setting, intestines were extracted from rats and imaged unfolded (Fig. 4B). For both groups, fluorescence was observed in the stomach, at $\mathrm{t}+1$ hour, (Fig. $4 \mathrm{~B}$ a and e). For the rats with the magnet, fluorescence was very intense and localized in the upper part of the intestine (Fig. 4B a-d). For the control rats, fluorescence was dispersed and located lower in the intestine (Fig. 4B f-g). When magnetic retention was used, fluorescence images showed a stronger and localized intensity. This high and localized fluorescence intensity was due to beads accumulation and slower circulation time along the GI tract.

\subsection{Magnetic retention: pharmacokinetics study}

Pharmacokinetics study was performed to investigate the effect of magnetic retention on the bioavailability of the drug. Indeed, magnetic retention efficiency to retain the magnetic beads in vivo in the upper part of the intestine has been demonstrated by imaging. For this study the rats were fasted for 12 hours before beads administration. Three groups of three rats were used for this study. In the first group $(n=3)$, the rats were fed magnetic beads containing the drug and a magnet was placed on their abdomen. The second $(n=3)$ and third groups $(n=3)$ were the controls. In the second group, the rats were fed drug loaded magnetic beads, without the magnet. In the third group, the rats were fed with an aqueous solution of the drug. The first and second groups were to study the impact of magnetic retention of the beads on the 


\section{WILEY-VCH}

bioavailability of the drug. The second and third groups were used to study the impact of the formulation of the drug inside the magnetic beads on the bioavailability of the drug. For all the rats, the dose was $20 \mathrm{mg} / \mathrm{kg}$ (16 beads per animal, $0.5 \mathrm{mg}$ of drug/bead). Blood samples were taken at $\mathrm{t}+0,5,1,2,3,4$ and 6 hours after administration, then the drug concentration in plasma was measured by mass spectrometry. The drug concentrations (ng. $\left.\mathrm{mL}^{-1}\right)$ titrated in the plasma after oral administration of magnetic beads and retention with a magnet were compared to control rats without magnet and to rats fed with an aqueous solution of drug (Fig. S3), and are summarized in Fig. 5a. The peak plasma concentration $\left(\mathrm{C}_{\max }\right.$, Fig. $5 \mathrm{~b}$ and $\left.5 \mathrm{c}\right)$ of the drug was reached 2 hours after administration with a value of $43.7 \mathrm{ng} \cdot \mathrm{mL}^{-1}$ when magnetic retention was used compared to $15.7 \mathrm{ng} \cdot \mathrm{mL}^{-1}$ without magnet and $10.2 \mathrm{ng} \cdot \mathrm{mL}^{-1}$ for free drug administered in water. The increase in concentration found when magnetic retention was used was statistically relevant ( $p<0.05$, Student's $t$-test) when compared to both control groups $\left(* * p=0.0016\right.$ and $\left.{ }^{* * *} p=0.0002\right)$. As a consequence the area under the curve $\left(\mathrm{AUC}_{\mathrm{t}}\right.$, Fig. $5 \mathrm{~b}$ and 5c) which corresponds to the integral of the concentration-time curve (after a single dose) and represents the relative bioavailability of the drug, is 2.5 times higher for the group with magnet than that without magnet and even in the case of free drug administration (128 vs 53.2 and 40 h.ng. $\mathrm{mL}^{-1}$ ). This 2.5 -fold increase in relative bioavailability when magnetic retention was used was found to be statistically relevant for both control groups $(* p=0.0109$ and $* * p$ $=0.0074)$. The last blood sample was retrieved at $t+6$ hours after beginning of the experiment and the concentration of drug was $15.3,7.65$ and $1.53 \mathrm{ng} \cdot \mathrm{mL}^{-1}$, respectively for the three groups (Fig. 5a and 5b).

\subsection{Magnetic retention: toxicity study}

A preliminary toxicity study has been conducted after single administration of magnetic beads (16 beads per animal, $20 \mathrm{mg} \cdot \mathrm{kg}^{-1}$ of drug), in order to determine the circulation path of the MNP after administration and retention in the intestine. MNP are well known to be easily 


\section{WILEY-VCH}

accumulated in the spleen and liver. In this study, the iron content in spleen, liver and the faeces was measured by AAS after acid degradation. Histological examination of several organs was conducted in order to check that the accumulation of magnetic beads along the intestine did not induce any immune response from the endothelial barrier as well as the potential accumulation of iron nanoparticles in the liver and spleen.

\subsubsection{MNPs accumulation in the organs}

In this study iron content of liver, spleen, faeces were compared for two groups of rats. For the first group $(n=3)$, magnetic retention is used to maintain magnetic beads in the GIT up to 6 hours and for the control group $(n=3)$, animals did not receive any magnetic beads. The faeces were collected twice, from the beginning up to 6 hours after beads administration and from 6 to 24 hours after the beginning of the experiment. At $t+24$ hours, rats were sacrificed by exsanguination and their spleen and liver were collected. Iron content in every samples was determined using AAS (Fig. 6a). Iron amount obtained 24 hours after administration for the first group was similar to the control group in the spleen $\left(1.78 \mathrm{vs} 2.36 .10^{-6} \mathrm{~mol}\right)$ and liver (10.8 vs $10.7 .10^{-6} \mathrm{~mol}$ ), showing that no iron has been accumulated and that only endogenous iron was detected in the organs. The amount of iron in the faeces until 6 hours after administration for the first group was similar to the one of the control group $\left(17.3 .10^{-6} \mathrm{~mol} v \mathrm{~s}\right.$ $\left.11.8 .10^{-6} \mathrm{~mol}\right)$. However iron content increased significantly $\left(73.8 .10^{-6} \mathrm{~mol}\right)$ between 6 and 24 hours after administration compared to the value found for the controls $\left(20.3 .10^{-6} \mathrm{~mol}\right)$. The amount of iron recovered in the faeces from $t+6$ to $t+24$ hours for the first group was very similar to the total amount of iron introduced in the organism by the administration of the magnetic beads $\left(69.6 \cdot 10^{-6} \mathrm{~mol}\right)$. The total amount of iron introduced in the organism by the magnetic beads containing MNPs was eliminated and recovered in the faeces after the removal of the magnet from the abdomen of the rats at $t+6$ hours. 


\section{WILEY-VCH}

\subsubsection{Histology study}

After a single oral administration of magnetic and fluorescent chitosan-alginate core-shell beads to two groups of rats (with $(n=3)$ or without magnet $(n=3)$ ), several tissues (liver, spleen, fore stomach and glandular stomach, duodenum, jejunum, ileum and caecum) were harvested and stained for histological microscopic analysis. In the stomach and intestinal portions, no changes considered to be of toxicological relevance were noted among rats (with or without magnet) (Fig. 6b-d). In the liver, the absence of Perls positive cells (e.g., hepatocytes, Kupffer cells) was supportive of an absence of iron uptake (Fig. 6e). The minimal to slight presence of Perls positive macrophages seen in the spleen of rats was considered to be within the spontaneous background, in line with the physiological degradation of red blood cells (Fig. 6f). No relevant microscopic changes were observed in the different portions of stomach, small intestines and caecum.

\section{Discussion}

Iron oxide nanoparticles and the drug DPP4 inhibitor (Fig. S1), were co-encapsulated in a chitosan-alginate core-shell bead through an extrusion method. This method enables the encapsulation of a large amount of magnetic nanoparticles in the matrix of the biopolymer (28.3\% in weight after drying, approximately $10^{15}$ nanoparticles per bead) which is a key point regarding their magnetic properties. The magnetic moment of one bead has been measured by VSM $\left(\mu_{\mathrm{s}}=0.347 .10^{-4} \mathrm{~A} . \mathrm{m}^{2}\right)$ and the core-shell structure was evidenced by SEM. These core-shell beads are suitable for oral delivery because they are resistant in acidic media (stomach $\mathrm{pH}$ ), mucoadhesive, exhibit a superparamagnetic behavior and a very high entrapment efficiency of the drug (75\%). Another major advantage of our magnetic beads is that they cannot cross the GI membrane due to their millimeter-size. Therefore, the only material that is available for uptake by intestinal membrane to join the bloodstream is the encapsulated drug. This drug is an antidiabetic molecule referred as class III molecule (BCS 


\section{WILEY-VCH}

classification), however the formulation can be generalized to other hydrophilic drugs (Biopharmaceutical Classification System and Formulation Development, 2011; Blume and Schug, 1999; Lindenberg et al., 2004). One of the challenges regarding the formulation is to find a drug-release profile suitable for in vivo administration. In our case the maximum drug release profile of the dry beads of 6 hours is well adapted.

The proof of concept of the magnetic retention has been made in a previous ex vivo study where the amount of drug permeated through the membrane exhibited a threefold increase when magnetic carriers were maintained near the jejunum in Ussing chambers (A. Seth et al., 2014). In order to translate this concept in vivo, the magnetic charge of the beads as well as the magnetic field gradient were optimized. We evaluate the magnetic force applied by the external magnet on one magnetic bead to be $2.310^{-4} \mathrm{~N}$ if we consider a uniaxial force. That is one order of magnitude lower than the magnetic force involved in the case of the magnetic retention of a magnetic pill containing a permanent magnet and an external magnetic field similar to the one used in a previous study by B. Laulicht and co-workers (2-4 mN) (Laulicht et al., 2011). The gastric emptying forces $P_{\text {gastric }}$ calculated in fasted rats are of the order $50.10^{-5}$ N.cm ${ }^{-2}$ (Laulicht et al., 2010). The gastric force can be thus calculated to be $F_{\text {gastric }}=$ $\mathrm{P}_{\text {gastric }} \mathrm{S}=3.910^{-6} \mathrm{~N}$ for a $1 \mathrm{~mm}$ diameter bead. From our study we can conclude that the magnetic retention was efficient when the $F_{\text {mag }}$ was two orders of magnitude higher than $\mathrm{F}_{\text {gastric. }}$ This is a very simple model because in this case, the interaction between the magnet and the bead is considered to be uniaxial. However this is very helpful to predict the magnetic retention because the magnetic moment of one bead can be measured and the magnetic force can be calibrated in order to know the magnetic field strength at a given distance.

According to this physical consideration we prove the efficacy of the magnetic retention of the beads when we compared two situations, with and without magnet. The retention of the magnetic beads was confirmed in vivo using both fluorescent and magnetic beads. Magnetic 


\section{WILEY-VCH}

resonance and near infrared imaging were performed over a time-course of 6 hours. MRI show an accumulation of the magnetic beads under the magnet position up to 6 hours after the administration of the beads whereas for the controls the beads cannot be localized at a specific position in the intestine. According to the high-speed acquisition of the NIR imaging we are able to give more information about the dynamics of the bead along the intestine. In the case where the intestine is folded, NIR images confirm MRI observations. Accumulation of the fluorescence signal, representative of the beads can be found under the initial position of the magnet up to 6 hours after gavage when magnetic retention is used. However when the intestine is unfolded it is possible to visualize the localization of the fluorescent beads in the intestinal loops. Magnetic beads are always located upper in the intestine when the magnet is used compared to the controls but the beads are not retained at a fixed position during the gastric emptying. The effect of the magnetic retention seems to be more related to a slowdown of the circulation time of the beads. Moreover we observe a more intense signal in the situation with magnet most likely due to the magnetic accumulation of the beads. In fact magnetic dipole-dipole interaction may contribute to the formation of aggregates, leading to an over-concentration of the magnetic carriers.

The correlation with the pharmacokinetics study is very interesting because after a single dose administration $\left(20\right.$ mg. $\left.\mathrm{kg}^{-1}\right)$ in fasted rats we find a relative bioavailability of the drug 2.5 times higher when the magnet is used. The plasma concentrations of the drug were significantly higher after 2,4 and 6 hours $(p<0.05$, Student's $t$-test). The peak plasma concentration is reached 2 hours after administration that corresponds to the situation where the beads are still localized under the magnet near the absorption window of the drug (upper part of the intestine). After this time the circulation is slowed down and as a consequence the residence time in the region of interest is longer that can explain the increase of the drug plasma concentration.

In this study we prove that the magnetic retention is efficient in the case of a poorly available 
drug that presents the same physico-chemical characteristics than a lot of drugs.

Biocompatibility of the magnetic chitosan-alginate beads was investigated in the GI tract tissue as well as in the organs where the MNPs are well known to be accumulated. This study demonstrated that the total amount of iron contained in the magnetic beads is recovered in the faeces after the removal of the magnet from the abdomen of the rats at $t+6$ hours and digestion of these beads. The MNP are eliminated through the natural digestion route in the faeces. In addition, microscopic analysis of histological tissue section of different organs did not exhibit any sign of inflammation or increase of iron accumulation, indicating a good tolerance of these formulations in vivo.

\section{Conclusion}

The core-shell formulation of magnetic beads developed in this study is well adapted to the encapsulation of highly soluble drugs and to their oral delivery. The magnetic retention technique was used to investigate the therapeutic benefit of prolonged local delivery of therapeutics at their site of greatest absorption. The beads may be easily detected in the GIT by NIR or MR imaging and the efficiency of the magnetic retention may be evidenced before starting the pharmacokinetics study. The design of the magnetic field and of the magnetic beads must be done so that the magnetic is two times higher than the gastric force depending on the model used. Unlike delivery by intra-venous injection, no magnetic nanoparticles were found in the organs. This is a key point because for long-term treatment we can envisage the use of formulation containing magnetic nanoparticles. Magnetic localization prolongs intimate contact between the drug and the absorptive GI epithelium promoting uptake and bioavailability without damaging intestinal tissue while providing visual confirmation of localization and quantitative force-sensing feedback in real time. 


\section{WILEY-VCH}

\section{Supporting Information}

Supporting Information is available from the Wiley Online Library or from the author.

\section{Acknowledgements}

The authors would like to thank Aude Michel for magnetic nanoparticles synthesis and iron spectrometry measurements; Michaël Trichet and the Service de Microscopie Electronique de l'IFR 83/FRE 3595 - CNRS-UPMC for the SEM images; all the technical support from Servier, Laure Pellé for her expertise on Ussing chambers; Catherine Caddor and Eric Jacquemin for their work with the animals. This research was supported by pharmaceutical company Servier and University Pierre et Marie Curie. Anjali Seth was financially supported by Servier.

Received: ((will be filled in by the editorial staff))

Revised: ((will be filled in by the editorial staff))

Published online: ((will be filled in by the editorial staff))

Amidon, G., Lennernäs, H., Shah, V., Crison, G., 1995. A theoretical basis for a biopharmaceutic drug classification : the correlation of in vitro drug product dissolution and in vivo bioavailability. Pharm. Res. 12, 413-420.

Andrews, G.P., Laverty, T.P., Jones, D.S., 2009. Mucoadhesive polymeric platforms for controlled drug delivery. Eur. J. Pharm. Biopharm. 71, 505-518.

doi:10.1016/j.ejpb.2008.09.028

Artursson, P., Karlsson, J., 1991. Correlation between oral drug absorption in humans and apparent drug permeability coefficients in human intestinal epithelial (Caco-2) cells. Biochem. Biophys. Res. Commun. 175, 880-885. doi:10.1016/0006-291X(91)91647-U

Bahnemann, R., Jacobs, M., Karbe, E., Kaufmann, W., Morawietz, G., Nolte, T., Rittinghausen, S., 1995. RITA--registry of industrial toxicology animal-data--guides for organ sampling and trimming procedures in rats. Exp. Toxicol. Pathol. 47, 247-66. doi:10.1016/S0940-2993(11)80259-9

Balimane, P. V, Chong, S., 2005. Cell culture-based models for intestinal permeability: a critique. Drug Discov. Today 10, 335-43. doi:10.1016/S1359-6446(04)03354-9

Bhardwaj, L., Sharma, P.K., Malviya, R., 2011. A Short Review on Gastro Retentive 
Formulations for Stomach Specific Drug Delivery: Special Emphasis on Floating In situ Gel Systems. African J. Basic Appl. Sci. 3, 300-312.

Biopharmaceutical Classification System and Formulation Development, FDA, 2011. http://www.fda.gov/AboutFDA/CentersOffices/OfficeofMedicalProductsandTobacco/C DER/ucm128219.htm

Blume, H.H., Schug, B.S., 1999. The biopharmaceutics classification system (BCS): Class III drugs — better candidates for BA/BE waiver? Eur. J. Pharm. Sci. 9, 117-121. doi:10.1016/S0928-0987(99)00076-7

Canfarotta, F., Piletsky, S., 2014. Engineered magnetic nanoparticles for biomedical applications. Adv. Healthc. Mater. 3, 160-175. doi:10.1002/adhm.201300141

Chen, H., Langer, R., 1998. Oral particulate delivery: Status and future trends. Adv. Drug Deliv. Rev. 34, 339-350.

Chen, H., Langer, R., 1997. Magnetically-responsive polymerized liposomes as potential oral delivery vehicles. Pharm. Res. 14, 537-540. doi: 10.1023/A:1012124205524

Cheng, J., Teply, B., Jeong, S.Y., Yim, C.H., Ho, D., Sherifi, I., Jon, S., Farokhzad, O.C., Khademhosseini, A., Langer, R.S., 2006. Magnetically responsive polymeric microparticles for oral delivery of protein drugs. Pharm. Res. 23, 557-564. doi:10.1007/s11095-005-9444-5

Chirra, H.D., Shao, L., Ciaccio, N., Fox, C.B., Wade, J.M., Ma, A., Desai, T., 2014. Planar microdevices for enhanced in vivo retention and oral bioavailability of poorly permeable drugs. Adv. Healthc. Mater. 3, 1648-54. doi:10.1002/adhm.201300676

Davis, S.S., 2005. Formulation strategies for absorption windows. Drug Discov. Today 10, 249-257. doi: 10.1016/S1359-6446(04)03351-3

Eiamtrakarn, S., Itoh, Y., Kishimoto, J., Yoshikawa, Y., Shibata, N., Murakami, M., Takada, K., 2002. Gastrointestinal mucoadhesive patch system (GI-MAPS) for oral administration of G-CSF, a model protein. Biomaterials 23, 145-52. doi.org/10.1016/S0142-9612(01)00089-8

Gamboa, J.M., Leong, K.W., 2013. In vitro and in vivo models for the study of oral delivery of nanoparticles. Adv. Drug Deliv. Rev. 65, 800-10. doi:10.1016/j.addr.2013.01.003

Gröning, R., Berntgen, M., Georgarakis, M., 1998. Acyclovir serum concentrations following peroral administration of magnetic depot tablets and the influence of extracorporal magnets to control gastrointestinal transit. Eur. J. Pharm. Biopharm. 46, 285-291. doi: $10.1016 /$ S0939-6411(98)00052-6

Häfeli, U.O., 2004. Magnetically modulated therapeutic systems. Int. J. Pharm. 277, 19-24. doi:10.1016/j.ijpharm.2003.03.002

Hari, P.R., Chandy, T., Sharma, C.P., 1996. Chitosan/calcium—alginate beads for oral delivery of insulin. J. Appl. Polym. Sci. 59, 1795-1801. doi:10.1002/(SICI)10974628(19960314)59:11<1795::AID-APP16>3.3.CO;2-F

Helliwell, M., 1993. The use of bioadhesives in targeted delivery within the gastrointestinal tract. Adv. Drug Deliv. Rev. 11, 221-251. doi:10.1016/0169-409X(93)90011-R

Ito, R., Machida, Y., Sannan, T., Nagai, T., 1990. Magnetic granules: A novel system for specific drug delivery to esophageal mucosa in oral administration. Int. J. Pharm. 61, 109-117. doi:10.1016/0378-5173(90)90049-A 
Laulicht, B., Gidmark, N.J., Tripathi, A., Mathiowitz, E., 2011. Localization of magnetic pills. Proc. Natl. Acad. Sci. U. S. A. 108, 2252-2257. doi:10.1073/pnas.1016367108

Laulicht, B., Tripathi, A., Schlageter, V., Kucera, P., Mathiowitz, E., 2010. Understanding gastric forces calculated from high-resolution pill tracking. Proc. Natl. Acad. Sci. U. S. A. 107, 8201-8206. doi:10.1073/pnas.1002292107

Levy, M., Luciani, N., Alloyeau, D., Elgrabli, D., Deveaux, V., Pechoux, C., Chat, S., Wang, G., Vats, N., Gendron, F., Factor, C., Lotersztajn, S., Luciani, A., Wilhelm, C., Gazeau, F., 2011. Long term in vivo biotransformation of iron oxide nanoparticles. Biomaterials 32, 3988-99. doi:10.1016/j.biomaterials.2011.02.031

Lindenberg, M., Kopp, S., Dressman, J.J.B., 2004. Classification of orally administered drugs on the World Health Organization Model list of Essential Medicines according to the biopharmaceutics classification system. Eur. J. Pharm. Biopharm. 58, 265-278. doi:10.1016/j.ejpb.2004.03.001

Massart, R., 1981. Preparation of aqueous magnetic liquids in alkaline and acidic media. IEEE Trans. Magn. 17, 1247-1248.

Nagano, H., Machida, Y., Iwata, M., Imada, T., Noguchi, Y., Matsumoto, A., Nagai, T., 1997. Preparation of magnetic granules containing bleomycin and its evaluation using model esophageal cancer. Int. J. Pharm. 147, 119-125. doi:10.1016/S0378-5173(96)04804-1

Nayak, A.K., Maji, R., Das, B., 2010. Gastroretentive drug delivery systems : a review. Asian J. Pharm. Clin. Res., 3 (1), 2-10.

Polyak, B., Friedman, G., 2009. Magnetic targeting for site-specific drug delivery: applications and clinical potential. Expert Opin Drug Deliv. 6(1), 53-70. doi: $10.1517 / 17425240802662795$.

Reed, K.K., Wickham, R., 2009. Review of the gastrointestinal tract: from macro to micro. Semin. Oncol. Nurs. 25, 3-14. doi:10.1016/j.soncn.2008.10.002

Salamat-Miller, N., Chittchang, M., Johnston, T.P., 2005. The use of mucoadhesive polymers in buccal drug delivery. Adv. Drug Deliv. Rev. 57, 1666-91. doi:10.1016/j.addr.2005.07.003

Sambuy, Y., Angelis, I. De, Ranaldi, G., Scarino, M.L., Stammati, A., Zucco, F., 2005. The Caco-2 cell line as a model of the intestinal barrier : influence of cell and culture-related factors on Caco-2 cell functional characteristics. Cell. Biol. Toxicol. 21(1), 1-26. doi: 10.1007/s10565-005-0085-6.

Seth, A., Lafargue, D., Poirier, C., Péan, J.-M., Ménager, C., 2014. Performance of magnetic chitosan-alginate core-shell beads for increasing the bioavailability of a low permeable drug. Eur. J. Pharm. Biopharm. doi:10.1016/j.ejpb.2014.05.017

Sezer, A.D., Akbuğa, J. 1999. Release characteristics of chitosan treated alginate beads: I. Sustained release of a macromolecular drug from chitosan treated alginate beads. J. Microencapsul. 16(2), 195-203. doi: 10.1080/026520499289176.

Streubel, A., Siepmann, J., Bodmeier, R., 2006. Drug delivery to the upper small intestine window using gastroretentive technologies. Curr. Opin. Pharmacol. 6, 501-8. doi:10.1016/j.coph.2006.04.007

Suknuntha, K., Tantishaiyakul, V., Worakul, N., Taweepreda, W., 2011. Characterization of muco- and bioadhesive properties of chitosan, PVP, and chitosan/PVP blends and release of amoxicillin from alginate beads coated with chitosan/PVP. Drug Dev. Ind. Pharm. 37, 


\section{WILEY-VCH}

408-18. doi:10.3109/03639045.2010.518149

Teply, B. a., Tong, R., Jeong, S.Y., Luther, G., Sherifi, I., Yim, C.H., Khademhosseini, A., Farokhzad, O.C., Langer, R.S., Cheng, J., 2008. The use of charge-coupled polymeric microparticles and micromagnets for modulating the bioavailability of orally delivered macromolecules. Biomaterials 29, 1216-1223. doi:10.1016/j.biomaterials.2007.11.018

Vasir, J.K., Tambwekar, K., Garg, S., 2003. Bioadhesive microspheres as a controlled drug delivery system. Int. J. Pharm. 255, 13-32. doi:10.1016/S0378-5173(03)00087-5

Wang, F.-Q., Li, P., Zhang, J.-P., Wang, A.-Q., Wei, Q., 2011. pH-sensitive magnetic alginate-chitosan beads for albendazole delivery. Pharm. Dev. Technol. 16, 228-36. doi: $10.3109 / 10837451003592217$

Whitehead, K., Shen, Z., Mitragotri, S., 2004. Oral delivery of macromolecules using intestinal patches: Applications for insulin delivery. J. Control. Release 98, 37-45. doi:10.1016/j.jconrel.2004.04.013

Wittaya-areekul, S., Kruenate, J., Prahsarn, C., 2006. Preparation and in vitro evaluation of mucoadhesive properties of alginate/chitosan microparticles containing prednisolone. Int. J. Pharm. 312, 113-8. doi:10.1016/j.ijpharm.2006.01.003

You, J.B., Choi, A.Y., Baek, J., Oh, M.S., Im, S.G., Lee, K.E., Gwak, H.S., 2015. Application of Monodirectional Janus Patch to Oromucosal Delivery System. Adv. Healthc. Mater. 4, 2229-2236. doi:10.1002/adhm.201500416

Zhang, D., Sun, P., Li, P., Xue, A., Zhang, X., Zhang, H., Jin, X., 2013. A magnetic chitosan hydrogel for sustained and prolonged delivery of Bacillus Calmette-Guérin in the treatment of bladder cancer. Biomaterials 34, 10258-66.

doi:10.1016/j.biomaterials.2013.09.027 


\section{WILEY-VCH}

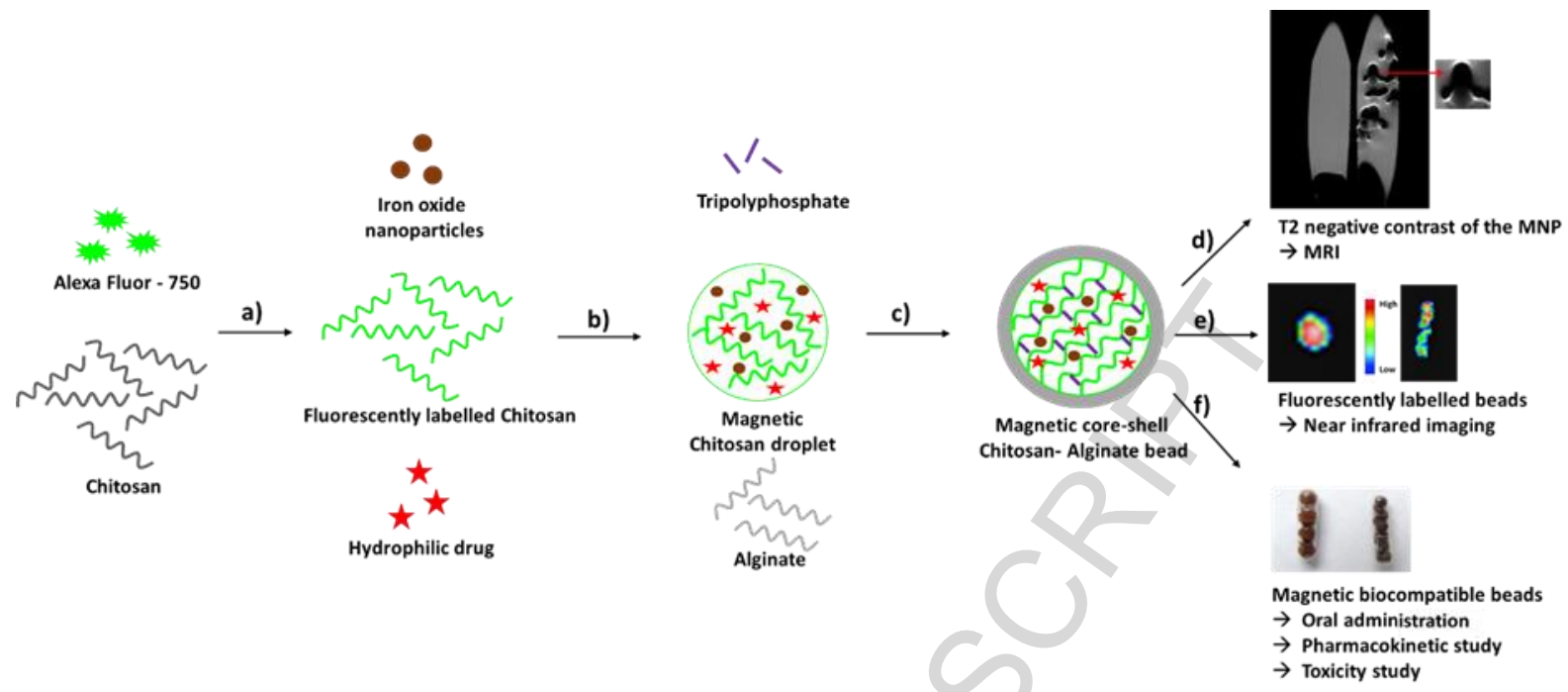

Fig. 1. Scheme of the synthesis of the magnetic and fluorescent core-shell chitosan-alginate beads. a) fluorescent labeling of the chitosan, b) formation of fluorescent chitosan beads containing MNPs and the drug, c) Crosslinking of the beads with tripolyphosphate and formation of the alginate shell, d) Imaging of the magnetic beads in MRI from left to right: tube containing agarose gel, tube containing magnetic beads embedded in agarose gel and zoom on one bead, e) Imaging of the magnetic beads in infrared fluorescence, from left to right: one magnetic beads and eight beads in a gelatin capsule, d) magnetic beads in a gelatin capsule for oral administration to the rats, four wet and eight dried beads. 

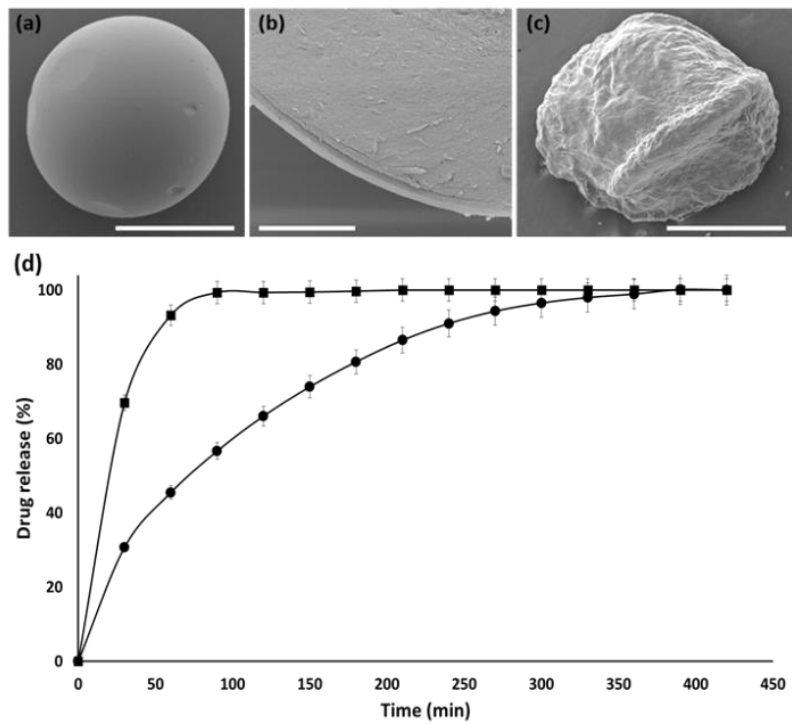

Fig. 2. (a)-(c) SEM images of the magnetic and fluorescent chitosan-alginate core-shell beads. (a) Whole bead (b) zoom on the shell after fracture of the bead and (c) whole bead after drying. Scale bars are $1 \mathrm{~mm}, 200 \mu \mathrm{m}$ and $1 \mathrm{~mm}$, respectively. (d) Drug release profile (\%) in function of time of the magnetic and fluorescent chitosan-alginate core-shell beads in the dissolution media $(\mathrm{pH}=6.8)(\boldsymbol{\square})$ before and $(\mathbf{O})$ after drying. 


\section{WILEY-VCH}

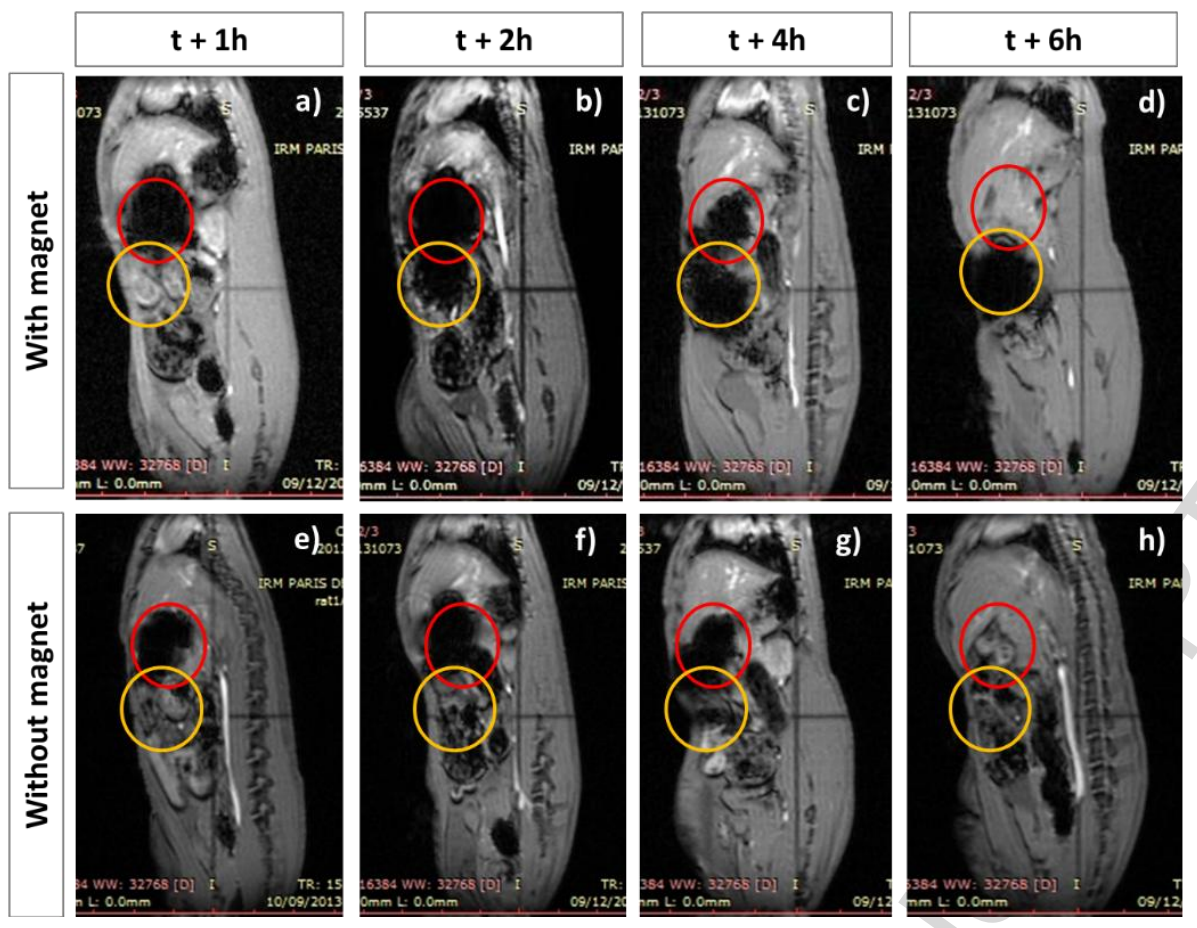

Fig. 3. MRI sagittal images of the rat after magnetic beads administration at time a) and e) 1 hour, b) and f) 2 hours, c) and g) 4 hours, d) and h) 6 hours after administration of the beads in the stomach. a) to d) with magnet and e) to $h$ ) without magnet. The position of the stomach and the magnet are marked $\mathbf{O}$ and $\mathbf{O}$ respectively. 


\section{WILEY-VCH}
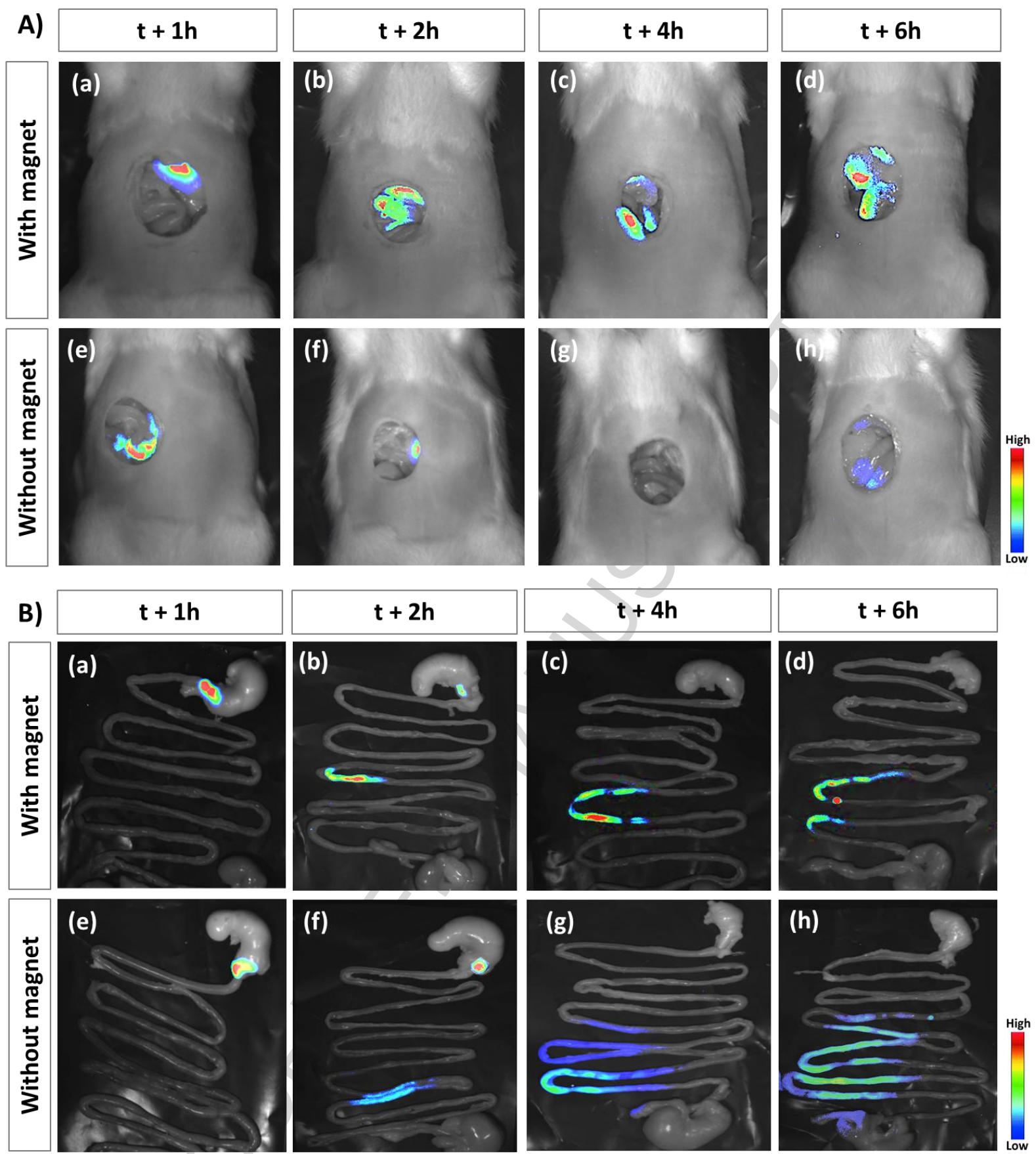

Fig. 4. Fluorescence and bright field merged images of the beads in the rats intestine A) under the magnet position, after skin removal and B) after unfolding the intestine from stomach to caecum at time a) and e) 1 hour, b) and f) 2 hours, c) and g) 4 hours, d) and h) 6 hours after administration of the beads in the stomach of the rats for animal a) to d) with magnet and e) to h) without magnet. 


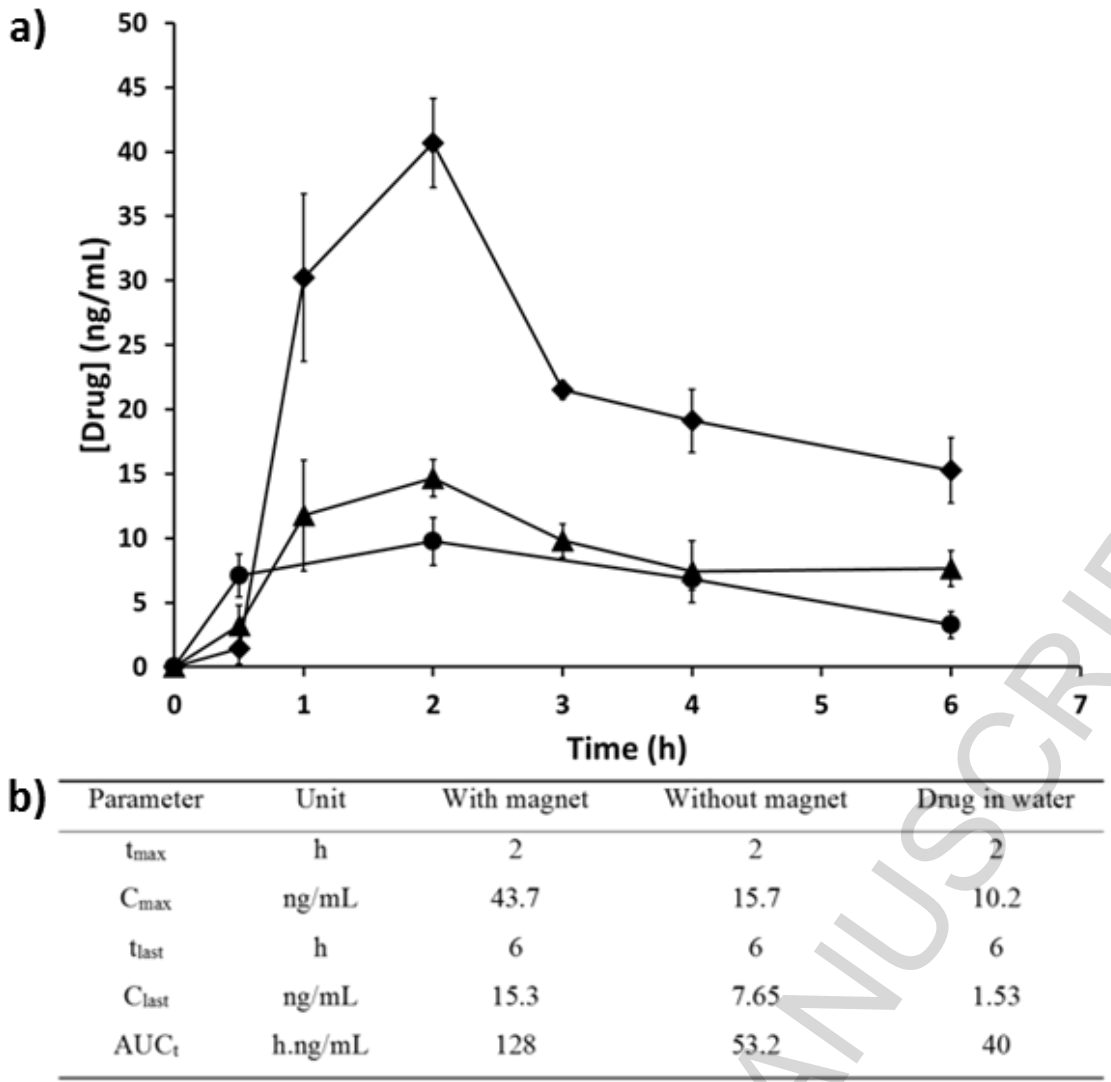

c)

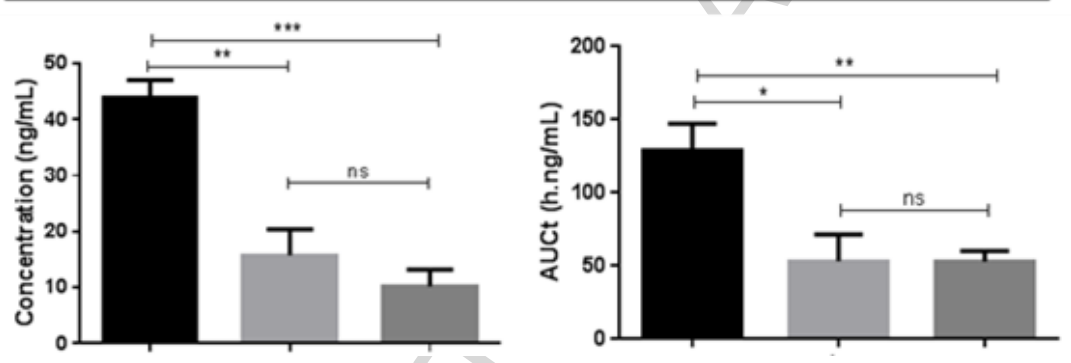

Fig. 5. a) Mean plasma concentration-time profiles following the oral administration of one single dose $(20 \mathrm{mg} / \mathrm{kg})$ of 15 magnetic beads with magnet, $(\mathbf{\Delta})$ without magnet and control rats administered with free drug $(n=3)$. b) Values of the pharmacokinetic parameters of the drug passage in blood for the three groups of rats $(n=3)$. c) Drug's maximum concentration at $\mathrm{t}=2$ hours $(\mathrm{ng} / \mathrm{mL})$ and AUCt $(\mathrm{h} . \mathrm{ng} / \mathrm{mL})$ for three groups $\mathbf{w i t h}$ magnet, without magnet and $\boldsymbol{\square}$ free drug (ns $\mathrm{P}>0.05$, * $\mathrm{P}<0.05$, ** $\mathrm{P}<0.01$, *** $\mathrm{P}<0.005$ ). 
WILEY-VCH
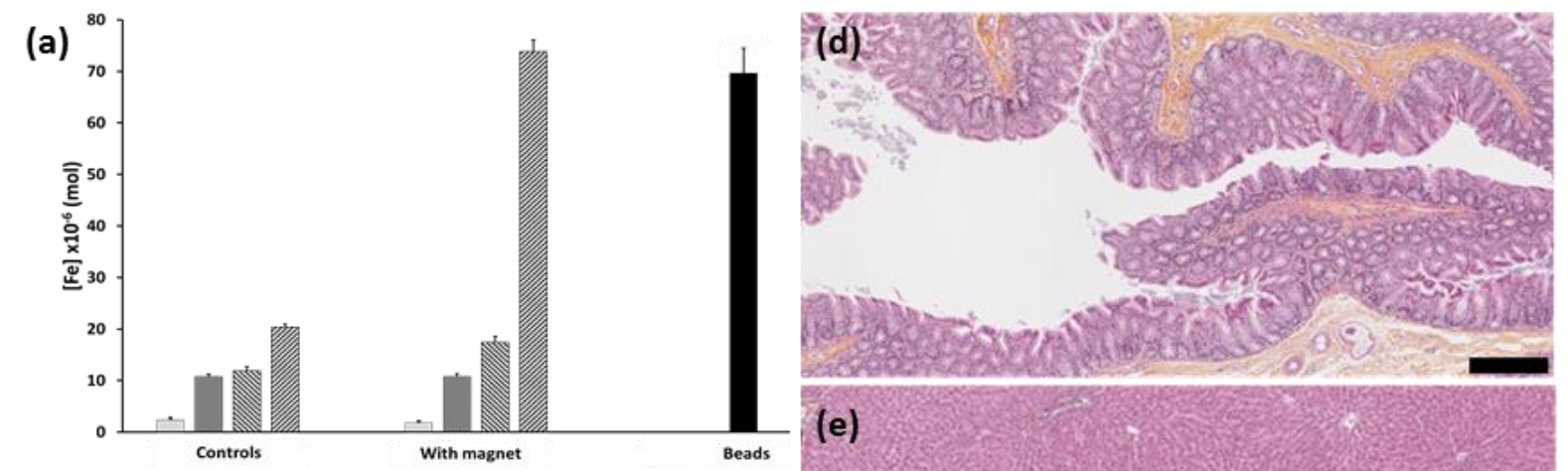

(e)
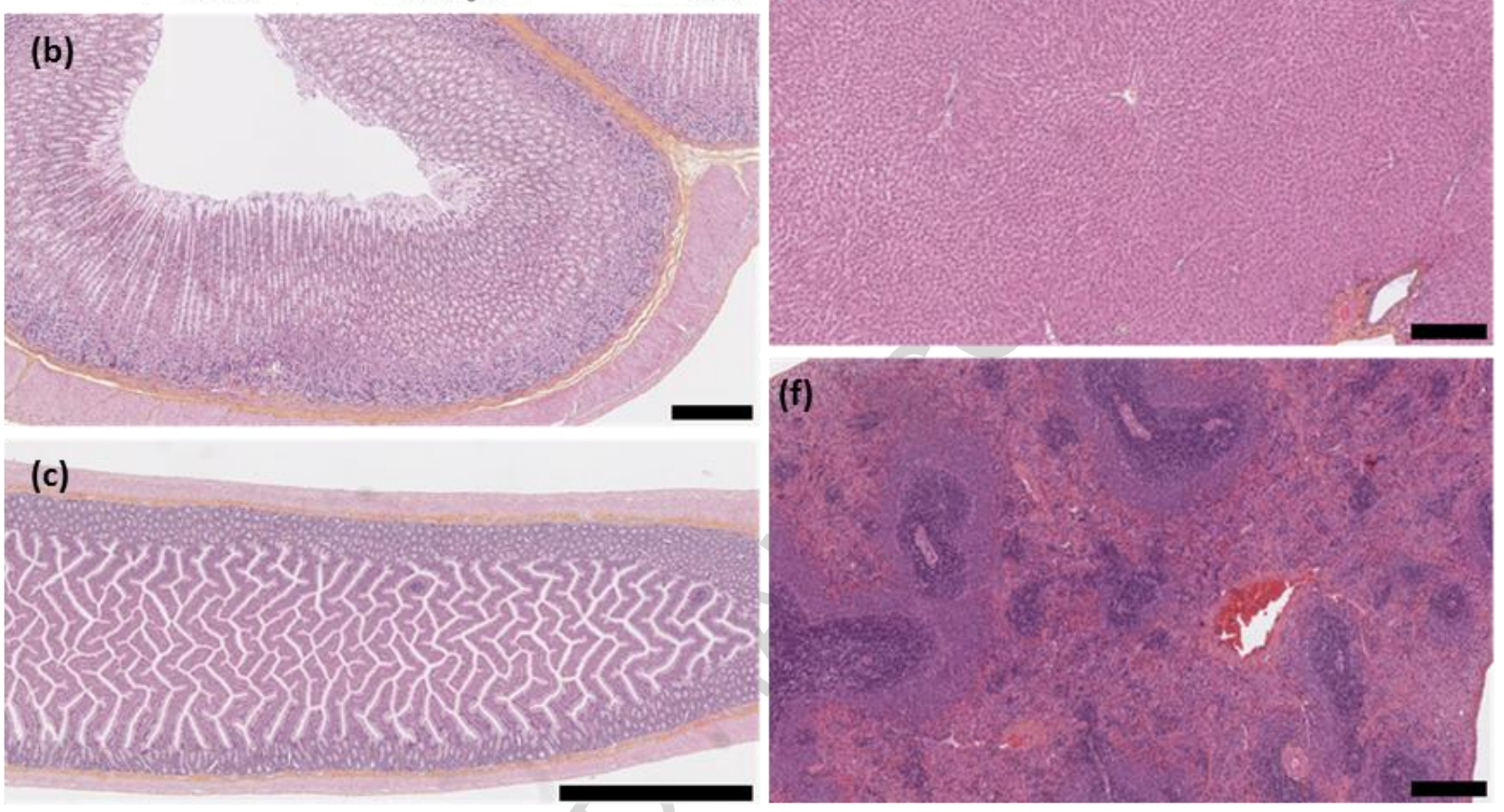

Fig. 6. (a) Iron content $\left(10^{-6} \mathrm{~mol}\right)$ in the spleen $(\boldsymbol{\square})$, in the liver ( $\left.\boldsymbol{\square}\right)$ and in the faeces at $0<\mathrm{t}<6 \mathrm{~h}(\mathrm{III})$ and $6<\mathrm{t}<24 \mathrm{~h}(/ / /)$ in comparison with the amount of iron in 15 beads $(\boldsymbol{\square})$.

Microscopy images of the histological slides of rats after magnetic beads administration and accumulation with a magnet at time $t+6$ hours from (b) stomach, (c) jejunum (d) caecum, (e) liver and (f) spleen. Scale bars are $1 \mathrm{~mm}$. 


\section{WILEY-VCH}

ToC

Magnetic retention of core-shell chitosan-alginate beads containing iron oxide nanoparticles is investigated for bioavailability improvement of a low permeable drug. The efficiency of magnetic retention in the intestine is observed by Magnetic Resonance and Near Infra-red imaging. The impact on drug's bioavailability as well as the toxicity of these magnetic carriers is then studied in vivo in the gastro intestinal tract.

Keywords: Oral delivery, Magnetic retention, Magnetic beads, Dual imaging, Pharmacokinetic.

A. Seth, D. Lafargue, C. Poirier, T. Badier, N. Delory, A. Laporte, J.-M. Delbos, V. Jeannin, J.-M. Péan and C. Ménager*

Optimization of Magnetic Retention in the Gastrointestinal Tract: Enhanced Bioavailability of Poorly Permeable Drug

Graphical Abstract

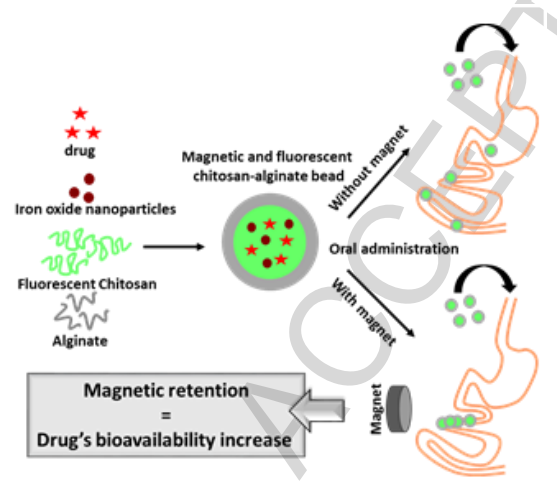

